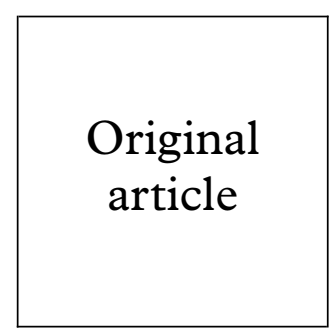

Centers for Disease

Control and

Prevention, Division of

HIV/AIDS Prevention,

Atlanta, GA, USA

M L Kamb

T A Peterman

City of Long Beach

Health Department,

Long Beach, CA, USA

F Rhodes

Colorado Department of Public Health and

Environment, Denver,

CO, USA

T Hoxworth

New Jersey Health

Department, Newark

STD Clinic, Newark,

NJ, USA

J Rogers

Baltimore City Health

Department,

Baltimore, MD, USA

A Lentz

San Francisco City

Clinic, San Francisco,

CA, USA

C Kent

Centers for Disease

Control and

Prevention, Division of

STD Prevention,

Atlanta, GA, USA

$\mathrm{R}$ MacGowen

Correspondence to:

Dr Mary L Kamb, Centers

for Disease Control and

Prevention, Division of

HIV/AIDS Prevention;

Mailstop E-46, 1600 Clifton

Road, NE, Atlanta,

GA 30333, USA.

Accepted for publication 26 May 1998

\title{
What about money? Effect of small monetary incentives on enrolment, retention, and motivation to change behaviour in an HIV/STD prevention counselling intervention
}

\author{
Mary L Kamb, Fen Rhodes, Tamara Hoxworth, Judy Rogers, Andrew Lentz, \\ Charlotte Kent, Robin MacGowen, Thomas A Peterman, for the Project RESPECT \\ Study Group
}

\begin{abstract}
Objectives: We studied the effect of small monetary incentives and non-monetary incentives of similar value on enrolment and participation in clinic based HIV/STD prevention counselling. We examined incident STDs to try to assess whether participants offered money may be less motivated to change risky behaviours than those offered other incentives.

Methods: Patients from five US STD clinics were invited to enrol in a multisession risk reduction counselling intervention and, based on their enrolment date, were offered either $\$ 15$ for each additional session or non-monetary incentives worth $\$ 15$. The two incentive groups were compared on participants' enrolment, completion of intervention sessions, and new STDs over the 24 months after enrolment.

Results: Of 648 patients offered money, 198 (31\%) enrolled compared with 160 (23\%) of 696 patients offered other incentives $(p=0.002)$. Enrollees in the two incentive groups had similar baseline characteristics, including condom use. Of the 198 participants offered money, 109 $(55 \%)$ completed all sessions compared with $59(37 \%)$ of the participants offered other incentives $(\mathrm{p}<0.0001)$. Comparing those offered money with those offered other incentives STD rates were similar after 6,12 , and 24 months.

Conclusions: Small monetary incentives enhanced enrolment and participation compared with other incentives of similar value. Regardless of incentive offered, participants had similar post-enrolment STD rates, suggesting that the type of incentive does not adversely affect motivation to change behaviour. Money may be useful in encouraging high risk individuals to participate in and complete counselling or other public health interventions. (Sex Transm Inf 1998;74:253-255)
\end{abstract}

Keywords: incentives; money; intervention evaluation; HIV prevention; STD clinic patients

\section{Introduction}

Although the effect of monetary incentives on enhancing recruitment and retention has been assessed in longitudinal research studies, ${ }^{12}$ little is published on their use in clinical or prevention programmes. Some authors suggest that monetary incentives may even counter effective behaviour change because the motivation driving intervention attendance may be the money rather than a true desire to change specific behaviours. ${ }^{34}$ Thus, while paid participants may be more likely than unpaid participants to accept and participate in an intervention, they may be less motivated to make the behaviour changes encouraged in the intervention.

As part of formative research for a randomised trial evaluating the efficacy of prevention counselling in reducing high risk behaviours and new sexually transmitted diseases (STDs) among patients attending public clinics, we examined the use of small monetary incentives on recruitment and intervention retention. We also collected information on new STDs diagnosed after enrolment, assuming incident STDs might measure "motivation" to fully participate in the intervention. If participants offered money were less motivated to change their behaviours than participants offered other incentives, those given money might be less likely to adapt safe behaviours, and more likely to develop new STDs.

\section{Methods}

Study participants were men and women attending five inner city STD clinics located in Baltimore, Maryland; Denver, Colorado; Long Beach and San Francisco, California; and Newark, New Jersey. From August to the end of October 1992, patients awaiting STD examination were asked if they would be willing to enrol in a series of risk reduction counselling sessions held at the clinic. Eligible patients must have come for a full STD examination, have been HIV negative (to their knowledge), and willing to have an HIV test. Potential participants were told that they would be offered a small incentive after each additional session (not including the first session) as a "thank you" for enrolling. Depending on the visit date, the incentive described was either $\$ 15$ cash or goods or certificates valued at $\$ 15$.

The "intervention" consisted of an interactive, face to face counselling session with a trained HIV counsellor on the day of visit, one additional group session moderated by the counsellor, and either one (Baltimore and 
Newark) or two (San Francisco, Denver, and Long Beach) additional face to face counselling sessions. Although the total number of sessions varied by site, the overall content of the intervention was similar. ${ }^{5}$ The first session was 20 minutes, the group session 90 minutes, and additional face to face sessions 60 minutes each; all sessions were done within 3 weeks. Before the first counselling session, participants were interviewed using a structured questionnaire.

At each site, there were two 2 week enrolment periods. Participants enrolled during one enrolment period were offered $\$ 15$ for each additional counselling session. During the other enrolment period, participants were offered goods or certificates (for example, grocery or restaurant gift certificates; movie tickets; subway or bus tokens) worth $\$ 15$ for each additional session. Non-monetary incentives varied by site and were chosen from items suggested as being important in patient surveys and focus groups

Table 1 Sex partner and condom use characteristics reported by participants at baseline, by incentive group

\begin{tabular}{|c|c|c|c|}
\hline \multirow[b]{2}{*}{ Characteristic } & \multicolumn{2}{|c|}{ Incentive group } & \multirow[b]{2}{*}{$p$ Value $^{*}$} \\
\hline & $\begin{array}{l}\text { Money } \\
(n=198)\end{array}$ & $\begin{array}{l}\text { Other } \\
(n=160)\end{array}$ & \\
\hline Male & $59 \%$ & $59 \%$ & \\
\hline Female & $41 \%$ & $41 \%$ & 0.38 \\
\hline Number of sex partners past 3 months (median) & 2 & 2 & \\
\hline Vaginal sex in past 3 months & $97 \%$ & $95 \%$ & 0.48 \\
\hline $\begin{array}{l}\text { Any condom use with vaginal sex } \dagger \\
\% \text { condom use: }\end{array}$ & & 0.32 \\
\hline None & $47 \%$ & $44 \%$ & \\
\hline$<50 \%$ & $25 \%$ & $30 \%$ & \\
\hline$>50 \%$ & $11 \%$ & $20 \%$ & \\
\hline $100 \%$ & $17 \%$ & $7 \%$ & 0.22 \\
\hline Anal sex in past 3 months $\ddagger$ & $9 \%$ & $7 \%$ & 0.79 \\
\hline Had a main partner (MP) $\int$ in past 3 months & $78 \%$ & $71 \%$ & 0.32 \\
\hline Any condom use with MP & $33 \%$ & $38 \%$ & 0.54 \\
\hline \multicolumn{4}{|l|}{ How easy was it to use condoms with MP? } \\
\hline Very easy & $41 \%$ & $47 \%$ & \\
\hline Fairly easy & $26 \%$ & $17 \%$ & \\
\hline Fairly hard & $19 \%$ & $23 \%$ & \\
\hline Very hard & $14 \%$ & $14 \%$ & 0.49 \\
\hline Had non-main sex partners (OP) $\llbracket$ in past 3 months & $49 \%$ & $56 \%$ & 0.23 \\
\hline Any condom use with OP & $55 \%$ & $52 \%$ & 0.72 \\
\hline \multicolumn{4}{|l|}{ How easy was it to use condoms with OP? } \\
\hline Very easy & $65 \%$ & $49 \%$ & \\
\hline Fairly easy & $23 \%$ & $32 \%$ & \\
\hline Fairly hard & $10 \%$ & $15 \%$ & \\
\hline Very hard & $3 \%$ & $4 \%$ & 0.52 \\
\hline
\end{tabular}

^By Mantel-Haenszel $\chi^{2}$ test (for 2 categories) or test for trend (if more than 2 categories). †Overall condom use and proportionate condom use were similar among men and women. $\ddagger$ Anal sex during past 3 months was reported similarly among men $(8 \%)$ and women $(8 \%)$. \Women reported a main partner more often than men ( $77 \%$ women $v 69 \%$ men, $\mathrm{p}=0.12)$.

TWomen reported non-main sex partner(s) less often than men (35\% women $v 69 \%$ men, $\mathrm{p}<0.001$ )

Table 2 Enrolment and participation in interventions, by incentive arm, by study site

\begin{tabular}{|c|c|c|c|c|c|}
\hline \multirow[b]{2}{*}{ Site } & \multirow[b]{2}{*}{ Incentive } & \multirow[b]{2}{*}{$\begin{array}{l}\text { Invited } \\
\text { No }\end{array}$} & \multirow[b]{2}{*}{$\begin{array}{l}\text { Enrolled } \\
\text { No (\%) }\end{array}$} & \multicolumn{2}{|c|}{ Participants attending: } \\
\hline & & & & $\begin{array}{l}1 \text { extra session } \\
\text { No }(\%)\end{array}$ & $\begin{array}{l}\text { All sessions } \\
\text { No (\%) }\end{array}$ \\
\hline \multirow[t]{2}{*}{ Baltimore } & Money & 67 & $29(43)$ & $13(45)$ & $8(28)$ \\
\hline & Other incentives & 95 & $36(38)$ & $9(25)$ & $9(25)$ \\
\hline \multirow[t]{2}{*}{ Denver } & Money & 262 & $26(11)$ & $14(54)$ & $13(50)$ \\
\hline & Other incentives & 292 & $30(10)$ & $19(63)$ & $19(63)$ \\
\hline \multirow[t]{2}{*}{ Long Beach } & Money & 122 & $50(41)$ & $20(60)$ & $29(58)$ \\
\hline & Other incentives & 98 & $33(34)$ & $16(48)$ & $13(39)$ \\
\hline \multirow{2}{*}{ Newark } & Money & 49 & $41(84)$ & $30(73)$ & $30(73)$ \\
\hline & Other incentives & 88 & $35(40)$ & $13(37)$ & $8(23)$ \\
\hline \multirow[t]{2}{*}{ San Francisco } & Money & 148 & $52(35)$ & $46(88)$ & $29(56)$ \\
\hline & Other incentives & 122 & $26(21)$ & $17(65)$ & $10(38)$ \\
\hline \multirow[t]{3}{*}{ Total } & Money & 648 & $198(31)$ & $133(67)$ & $109(55)$ \\
\hline & Other incentives & 696 & $160(23)$ & $74(46)$ & $59(37)$ \\
\hline & & & $\mathrm{p}=0.002$ & $\mathrm{p}<0.0001$ & $\mathrm{p}<0.0001$ \\
\hline
\end{tabular}

conducted at the clinics. At two sites, San Francisco and Denver, payment was offered during the first enrolment period; at the other sites payment was offered during the second period. The non-random study design was used to avoid patients enrolled on the same day finding out that other patients had received a different, and perhaps more desirable, incentive.

We reviewed participants' STD clinic records for the 24 months following enrolment to assess new STDs diagnosed at the clinics, comparing rates among those offered money with those offered non-monetary incentives. At all clinics, patients undergoing examination had urethral or cervical culture for Neisseria gonorrhoeae and serological tests for syphilis. Women had a wet mount for trichomonas, and men with urethral discharge had a Gram stain assessing presence of white cells and Gram negative intracellular diplococci. Tests were collected using standard procedures, ${ }^{6}$ and symptomatic patients or those who had sex partners with STDs were treated according to standard recommendations. ${ }^{7}$ (Chlamydia testing was not routinely done at the clinics.) We calculated proportions and used $\chi^{2}$ or two tailed Fisher's exact tests to test differences between categorical variables. ${ }^{8}$

\section{Results}

Of 1344 patients offered the intervention, 358 (27\%) agreed to participate. Participants comprised $211(24 \%)$ of the eligible men and 147 $(32 \%)$ of the eligible women and ranged in age from 15 to 55 years (mean 26.7 years). Patients refusing the study were more likely than participants to be men but were similar in age and race/ethnicity. The most common reasons for refusal were not wanting an HIV test $(28 \%)$, job or school conflict $(24 \%)$, or being "too busy" (17\%); transportation problems, lack of child care, and belief that one was not at risk for HIV infection were uncommonly cited $(<1 \%$ each).

Enrolment was higher among the group offered money: 198 (31\%) of the 648 patients offered money enrolled as against $160(23 \%)$ of the 696 offered other incentives $(p=0.002)$. Participants in the two incentive groups were similar in sex (59\% male each group), age (mean 27 and 25 years respectively), and racial/ethnic background $(67 \%$ and $63 \%$ African-American respectively). Participants offered money and those offered other incentives reported similar demographic, sex partner, and condom use characteristics (table 1).

Intervention participation rates differed: compared with those offered other incentives, those offered money were more likely to attend at least one additional session (67\% money $v$ $46 \%$ other incentives; $\mathrm{p}<0.0001)$ and to complete all the scheduled intervention sessions $(55 \%$ v $37 \% ; \mathrm{p}<0.0001)$. This was true for men and women and for all study sites except Denver (table 2).

In the 24 months after enrolment, $85(40 \%)$ of the 211 men and $68(46 \%)$ of the 147 women who enrolled returned to the clinic (range 1-18 visits). Among the 358 enrolled, participants offered money and those offered 
other incentives had similar rates of new STD diagnoses at 6,12 , and 24 months $(10 \%$ at 24 months). Considering an STD event to include either an STD diagnosis in the participant or a presumptive STD in a sex partner, those offered money were slightly less likely to have an event than those offered other incentives $(20 \% v 29 \%, \mathrm{p}=0.051)$ at 24 months.

\section{Discussion}

The results suggest that small monetary incentives were more effective than non-monetary incentives of equal cost in enhancing enrolment and participation in clinic based, HIV/ STD prevention counselling interventions. Rates of new STDs were similar among participants offered money and those offered other incentives. To the extent that incident STDs measure motivation to change behaviour, the results suggest that money does not adversely affect motivation more than other types of incentives.

Regardless of incentive strategy used, the acceptance rates for this study were low. We were encouraged to observe that in subsequent pilot studies (using $\$ 15$ per session), enrolment was as high as $90 \%$ at some sites and $50 \%$ overall, and intervention completion was $82 \%$. ${ }^{9}$ We believe these higher enrolment and participation rates over time were related to a combination of staff experience and improved study operations.

This study has some limitations. We did not randomly assign participants to incentive strategies. That participants offered money and those offered other incentives were similar on measured demographic and behavioural variables suggests the two groups were similar; however, they may have differed on some unmeasured conditions. A potential limitation was use of post-enrolment STDs to measure motivation to change behaviour; we are not sure if STD outcomes are a good measure.
Although new STDs are probably underestimated, this is not likely to affect our results unless underestimation occurred differentially among incentive groups. However, the small number of new STDs may have limited our power to detect a true difference between the two groups.

\section{Project RESPECT Study Group}

Baltimore City Health Department: Carolyn Erwin-Johnson, MA; Andrew L Lentz, MPA; Mary A Staat, MD, MPH; Dawn Sweet, $\mathrm{PhD}$; Jonathan M Zenilman, MD (principal investigator (PI)) Denver Department of Public Health and Colorado Department of Public Health and Environment: John Douglas, MD (PI); Tamara Hoxworth, PhD; Ken Miller, MPH.

Long Beach Department of Health and Human Services: Ruth Bundy, PhD (co-PI); Laura A Hoyt, MPA; C Kevin Malotte, DrPH; Fen Rhodes, PhD (PI).

New fersey Department of Health: Michael Iatesta, MA; Eileen New Fersey Department of Health: Michael Iatesta, MA; Eileen
Napolitano (co-PI); Judy Rogers, MS; Ken Spitalny, MD (PI). San Francisco Department of Public Health: Gail A Bolan, MD San Francisco Department of Public Health: Gail A Bolan, MD
(PI); Coleen LeDrew, Kimberly A J Coleman; Luna Hananel, (PI); Coleen LeDrew, Kimberly

Centers for Disease Control and Prevention: Sevgi Aral, PhD; Beth Centers for Disease Control and Prevention: Sevgi Aral, PhD; Beth
Dillon, MSW; Martin Fishbein, PhD; Sandra Graziano, PhD; Mary L Kamb, MD, MPH; Thomas A Peterman, MD, MSc; and Karen L Willis, RN.

1 Capaldi D, Patterson GR. An approach to the problem for recruitment and retention rates for longitudinal research. Behavioral Assessment 1987;9:69-177.

2 Rudy EB, Estok PJ, Kerr ME, et al. Research incentives: money vs gifts. Nursing Research 1994;43:253-5.

3 Crano WE. Pitfalls associated with the use of financial incentives (and other complex manipulations) in human social research. Basic and Applied Social Psychology 1991;12: 369-90.

4 Folger R. Money, methods, and theory: on taking Crano seriously. Basic and Applied Social Psychology 1991;12:391404.

$5 \mathrm{Kamb} \mathrm{ML}$, Dillon BA, Fishbein M, et al for the Project RESPECT Study Group. Quality assurance of HIV prevention counseling in a multi-center randomized controlled trial. Public Health Rep 1996;(Suppl 1)111:99107.

6 Centers for Disease Control. Sexually transmitted disease clinical practice guidelines. Atlanta, Georgia: US Department of Health and Human Services, Center for Prevention Services, CDC, Public Health Service, 1991.

7 Centers for Disease Control. 1989 Sexually transmitted diseases treatment guidelines. MMWR 1989;38(no S-8).

8 SAS user's guide: statistics. SAS Institute Inc, 1985.

9 Graziano S, Berringer L, Douglas JM, et al for the Project Graziano S, Berringer L, Douglas JM, et al for the Project
RESPECT Study Group. Will STD clinic patients enroll in multiple session HIV/STD prevention counseling? Xth International Society for Sexually Transmitted Disease International Society for Sexually Transmitted Disease
Research, Helsinki, Finland, 29 August-1 September 1993 Research,
(No135). 